Vol. 1 (Juni 2019): $30-34$

\title{
PENINGKATAN KEMAMPUAN BERBICARA BAHASA INGGRIS MELALUI TEKNIK MEMBACA BERITA DI SMA DEK PADANG
}

\author{
${ }^{1}$ Edwar Kemal, ${ }^{2}$ Wahyudi Rahmat, ${ }^{3}$ Refa Lina Tiawati, ${ }^{4}$ Suci Dwinitia, \\ 1,2,3,4STKIP PGRI Sumatera Barat \\ *E-mail: ${ }^{1}$ edwarkemal@gmail.com, ${ }^{2}$ wahyudirahmat24@gmail.com, ${ }^{3}$ refa@stkip-pgri-sumbar.ac.id, \\ ${ }^{4}$ suci@stkippgri-sumbar.ac.id
}

Submited: 2019.01.23 Reviewed: 2019.01.28 Accepted:2019.06.30

https://doi.org/10.22202/rangkiang.2019.v1.i1.37334

\begin{abstract}
Learning English, especially speaking skills, requires a variety of accurate strategies. The aim is to make it easier for students to learn English, the more ways they can learn it the easier it is to master it. However, it is important to remember that learning English is not learning knowledge that requires high logical reasoning, memorizing formulas, mastering tenses, grammar, and formal English grammar, and so on. But learning English is nothing more than a skill that is continuously practiced until it is accustomed, any language learned requires the practice of speaking the language learned.
\end{abstract}

Keywords: speaking ability, news reading technique, high school

\section{ABSTRAK}

Mempelajari bahasa Inggris khususnya keterampilan berbicara membutuhkan bermacam strategi yang jitu. Tujuannya adalah mempermudah siswa mempelajari mata pelajaran bahasa Inggris, semakin banyak cara yang dilakukan untuk belajar maka semakin mudah menguasainya. Akan tetapi perlu diingat bahwa belajar bahasa Inggris bukan belajar pengetahuan yang memerlukan daya nalar yang tinggi, menghafal rumus-rumus, menguasai tenses, grammar, dan tata bahasa Inggris yang formal, dan lain-lain. Namun belajar bahasa Inggris tidak lebih dari keterampilan (skill) yang terus menerus dipraktikkan sampai terbiasa, bahasa apapun yang dipelajari membutuhkan praktik berbicara dengan bahasa yang dipelajari.

Kata kunci: kemampuan berbicara, teknik membaca berita, SMA

PENDAHULUAN

Pengabdian kepada masyarakat merupakan salah satu dharma atau tugas pokok dari suatu perguruan tinggi termasuk STKIP PGRI Sumbar, di samping dharma pendidikan dan pengajaran serta dharma penelitian. Pelaksanaan dharma pengabdian kepada masyarakat yang dalam realisasinya juga melibatkan dua dharma lainnya. Oleh karena pengabdian kepada masyarakat merupakan salah satu tugas pokok Perguruan Tinggi, maka pelaksanannya harus didukung oleh seluruh sivitas akademika PT tersebut dan dilandasi pemahaman yang benar tentang pengabdian kepada masyarakat sesuai dengan PP 60/99 (BAB III pasal 3 ayat 4) yang menyatakan bahwa "Pengabdian masyarakat merupakan kegiatan yang memanfaatkan ilmu pengetahuan dalam upaya memberikan sumbangan demi kemajuan masyarakat".

Kemampuan dalam berbicara dalam berbahasa inggris melalui teknik dalam mebaca berita dapat melatih keterampilan memyimak dan berbicara siswa dalam berbhasa inggris. Karena di dalam kemampuan berbahasa inggris ada beberapa komponen, yaitu pronunciation, intonation, sentence stress, grammar dan vocabulary yangn perlu dikembangka di dalam berlajar bahasa inggris.

Pronunciation, Melafalkan kata atau kalimat dalam Bahasa Inggris tidaklah terlalu sulit bagi orang Indonesia, dengan demikian hal ini dapat dilatih dengan cepat dan mudah. Untuk meningkatkan kemampuan dalam area tersebut, pertama kita harus fokus dengan satu dialek atau aksen. Mengacu kepada dua aksen yang berbeda dapat menjadi hal yang membingungkan. 
Vol. 1 (Juni 2019): $30-34$

Intonation, Ketika seseorang sedang marah, intonasi yang digunakan akan berbeda ketika mereka sedang merasa senang. Begitu juga ketika seseorang sedang memimpin suatu pidato, intonasi mereka akan berbeda dengan mereka yang sedang melakukan presentasi. Intonasi adalah bagian penting dalam kemampuan berbicara Bahasa Inggris. Dengan penguasaan intonasi, percakapan akan terdengar alami dan tidak kaku atau robotic. Cara melatih keterampilan ini adalah dengan mempelajari ragam bunyi atau nada yang berbeda dalam speaking skills.

Sentence Stress, Tekanan pada kalimat adalah salah satu faktor yang mendukung meningkatnya kemampuan intonasi Bahasa Inggris. Keterampilan ini dapat menentukan kata kerja utama dalam kalimat, beserta subjek dan objek yang terkandung di dalamnya. Ketika kita mendengarkan percakapan dalam Bahasa Inggris, terkadang sang pembicara terkesan mengutarakan kalimat secara terburu-buru, hal ini memang ada benarnya, namun umumnya disebabkan karena kontraksi kalimat yang ada. Contohnya: "How was that cup of tea you have ordered before?" akan terdengar seperti "How's tha' cuppa tea you've ordered before?". Untuk melatih kemampuan ini, kalian dapat mendengarkan audiobooks, atau lagu Bahasa Inggris secara rutin dan berusaha mengikuti kembali kalimat atau lirik lagu yang ada.

Grammar,Meningkatkan Grammar Bahasa Inggris mampu menguatkan kemampuan berbicara kita dengan cara memperlancar keterampilan serta menambah kepercayaan diri ketika kita berusaha membentuk kalimat dalam Bahasa Inggris. Cara untuk meningkatkan keahlian ini, selain melalui latihan soal soal Grammar, kalian dapat menggunakan forum-forum English as a Second Language (ESL) untuk melatih Grammar kalian dengan para pelajar lain atau bahkan dengan native speaker. Vocabulary, Menampung kosakata sebanyak mungkin adalah langkah terakhir. Hal ini dapat dilakukan dengan banyak membaca buku Bahasa Inggris, dan menggunakan bantuan kamus untuk mendukung proses pembelajaran tersebut. Demikian beberapa komponen yang harus diperhatikan guna meningkatkan kemampuan berbicara Bahasa Inggris kalian

\section{METODE}

Metode yang digunakan adalah deskriptif, yaitu berupaya untuk memecahkan atau menjawab permasalahan yang sedang dihadapi situasi sekarang. Metode deskriptif banyak mempunyai manfaat, terutama dalam rangka mengadakan berbagai perbaikan. Suatu penelitian atau penagbdian yang dilakukan terhadap masalah metode mengajar tertentu misalnya, dapat mengungkapkan berbagai aspek terutama segi kebaikan dan kelemahan, serta sampai sejauh mana metode proses belajar mengajar (PBM) untuk suatu bidang studi tertentu. Metode ini dilakukan dengan menempuh langkah-langkah pengumpulan, klasifikasi, dan analisis atau pengolahan data, membuat kesimpulan dan laporan; dengan tujuan utama untuk membuat penggambaran tentang sesuatu keadaan secara obyektif dalam suatu deskripsi situasi. Setelah itu diambil langkah-langkah agar proses pengabdian dapat berjalan dengan baik dan bisa bermanfaat bagi siswa dan guru. Pelatihan tersebut menggunakan waktu 100 menit dengan perincian, 20 menit teori, 10 menit tanya-jawab, 10 menit diskusi, dan 60 menit pengamatanpembacaan berita dalam bahasa Inggris. Tujuan yang hendak dicapai melalui kegiatan pengabdian kepada masyarakat adalah sebagai berikut: (a) memberikan pemahaman dan pengetahuan bagi siswa dalam kemampuan berbicara bahasa inggris melalui teknik membaca berita di sma dek padang, dan (b) untuk memecahkanpermasalahanpada siswa dalam menpelajari bahasa Inggris terutam dalam kemampuan berbicara.

\section{HASIL DAN PEMBAHASAN}

Berbicara adalah mendengarkan dan memahami, atau bahkan membaca dan menulis; tetapi berbicara dengan penutur asli bahasa tersebut tanpa bingung dan berpikir. Dalam proses pembelajaran berbagai mata pelajaran memiliki cara-cara yang terbaik. Tujuannya adalah untuk membangkitkan potensi siswa belajar aktif, menyenangkan, dan benar benar menaruh minat 


\title{
Rangkiang: لLrnal Pengabdian Pada Masyarakat UPSM STKIP PGR/ Sumatera Barat
}

Vol. 1 (Juni 2019): $30-34$

terhadap mata pelajaran yang diberikan khususnya hal ini adalah mata pelajaran bahasa Inggris. Kata Guided berasal dari bahasa Inggris yang artinya membimbing, mengarahkan, menuntun, memberi tahu, menunjukkan, memandu dan memberikan semangat (Sadli, 1989: 201 dan Oxford, 1986: 308).

Dari arti kosa kata tentang Guided tersebut dapat digambarkan bahwa dalam proses pembelajaran salah satu tugas guru adalah memberikan, menuntun dan memandu siswa dengan sebaik mungkin untuk mendapatkan sesuatu yang diinginkan. Keinginan yang berkaitan dengan penguasaan dan peningkatan hasil belajar dalam bidang keterampilan berbicara bahasa Inggris. Dari beberapa arti kata Guided di atas, yang erat kaitannya dengan proses pembelajaran keterampilan berbicara bahasa Inggris adalah "membimbing dan memandu" siswa dalam belajar.

Antara membimbing dan memandu memiliki kesamaan makna dan tujuan karena kedua kata tersebut sama-sama menuntun siswa ke arah yang cemerlang (bisa berbicara) bahasa Inggris. Siswa yang sebelumnya masih banyak belum tahu bagaimana mengucapkan sebuah kata dalam bahasa Inggris (misalnya, mengucapkan book) yang kadang-kadang dibaca oleh siswa dengan bo-ok. Dengan tuntunan guru maka dari bo-ok menjadi (buk) dan banyak lagi kosa kata atau kalimat yang sulit dikatakan oleh siswa karena terbiasa dengan bahasa ibu atau Bahasa Indonesia dan bahasa daerah.

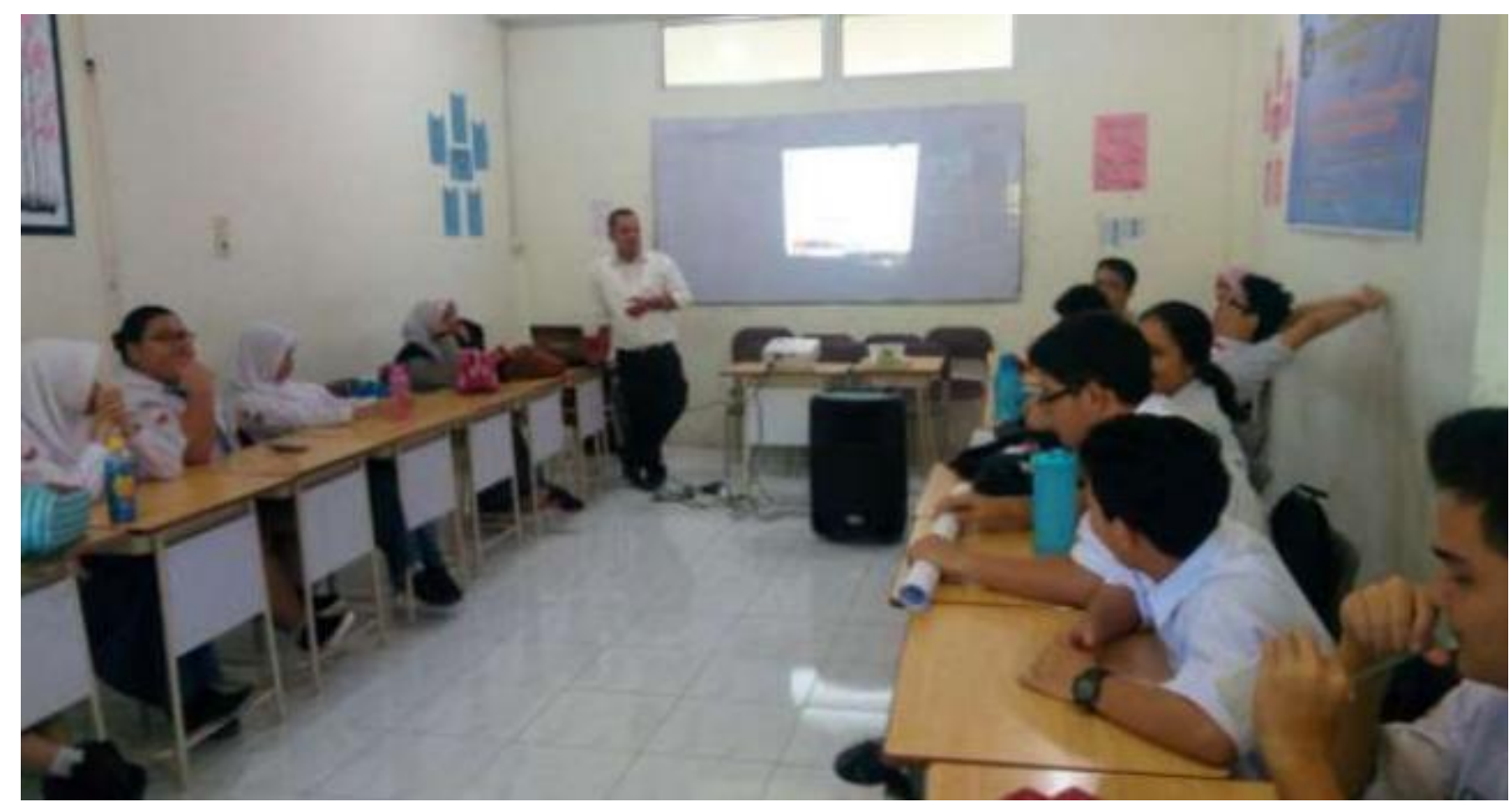

Tuntunan semacam ini yang dilakukan guru dalam proses pembelajaran keterampilan berbicara bahasa Inggris di dalam atau di luar kelas untuk memantapkan ucapan-ucapan siswa dalam bentuk percakapan sederhana seperti ungkapan di bawah ini: ini:

a. Salam (Greetings)

Biasanya setelah mengucapkan salam, diiringi dengan menanyakan kabar orang yang disapa. Di bawah ini beberapa ungkapan salam yang biasa digunakan serta ungkapan yang digunakan untuk menanyakan/menjawab kondisi seseorang yang disertai dengan tuntunan guru bahasa Inggris seperti dalam tabel di bawah ini.

\author{
Selamat Pagi Good Morning \\ Selamat Siang Good Afternoon \\ Selamat Malam Good Evening \\ Selamat Malam/Selamat \\ Tinggal/Selamat Tidur Good Night \\ Selamat Tinggal Good Bye
}


Sampai Jumpa See you

Halo atau Hai Hello atau $\mathrm{Hi}$

Apa kabar? How are you?

Baik-baik saja I'm fine. Thank you. atau Good

Apakah kamu baik-baik saja? Are you alright?atauAre you OK?

Saya sedang sakit I'm feeling sick atau I feel sick

Saya sedang pusing I'm having a headache

Saya sedang flu I'm having a flu/influenza

Saya demam I'm having a cold

Saya merasa tidak enak badan I am not feeling well

Yah, begitulah atau Biasa-biasa saja Not bad

b. Perkenalan diri (Introduction)

Berikut adalah ungkapan-ungkapan yang biasa digunakan untuk bertanya tentang identitas seseorang/memperkenalkan diri kepada orang lain dalam bentuk/kalimata bahasa Inggris sederhana dan disertai tuntunan atau bimbingan guru bahasa Inggris, sebagai berikut:

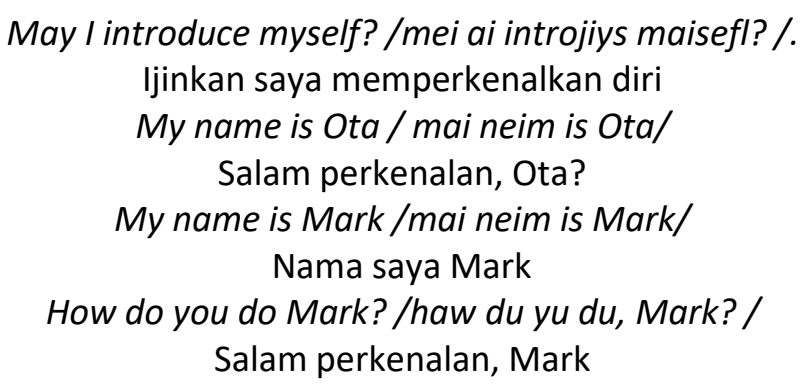

Dari tuntunan atau bimbingan yang dilakukan guru bahasa Inggris secara terus menerus maka diyakini bahwa peningkatan keterampilan siswa dalam berbicara bisa meningkat. Karena disamping bimbingan atau panduan guru terhadap ucapan siswa terhadap kalimat pendek bahasa Inggris di atas, juga dilengkapi dengan tuntunan ucapan yang tersedia di ujung kalimat bahasa Inggris. Dengan demikian, besar kemungkinan bagi siswa bisa melakukan praktik keterampilan berbicara bahasa Inggris sangat mudah.

Selanjutanya, kata "Conversation" berarti "percakapan atau perbincangan" (Hasan Sadli, 1989: 105). Menurut kamus Oxford (1986: 123) Conversation adalah a spoken exchange of news and ideas between people. Selanjutnya,dalam http://www.answers.com/topic/conversation (yang dikutip pada hari Sabtu, tanggal 11 Desember 2010) menyatakan bahwa conversation adalah sebagai berikut:

"A conversation is communicationbetween two or more people. Conversations are the ideal form of communication in some respects, since they allow people with different views on a topic to learn from each other. A speech, on the other hand, is an oral presentation by one person directed at a group. For a successful conversation, the partners must achieve a workable balance of contributions. A successful conversation includes mutually interesting connections between the speakers or things that the speakers know. For this to happen, those engaging in conversation must find a topic on which they both can relate to in some sense. Those engaging in conversation naturally tend to 
Vol. 1 (Juni 2019): $30-34$

relate the other speaker's statements to themselves. They may insert aspects of their lives into their replies, to relate to the other person's opinions or points of conversation.

Dari kutipan di atas, dapat digambarkan bahwa percakapan adalah terjadinya komunkiasi yang dilakukan oleh beberapa orang dalam rangka memberikan pandangan, pemikiran, usulan dan solusi. Dalam percakapan yang panjang akan menghasilkan sebuah kesepakatan bersama secara positif dan hasilnya disebarkan kepada segenap orang yang berkepentingan terhadap hasil kesepatan itu. Semua kesepakatan dari percakapan itu harus dipatuhi bersama-sama karena kegunaannya untuk bersama.

Berhubungan dengan keterampilan berbicara bahasa Inggris, berarti memberdayakan siswa agar dapat melakukan keterampilan berbicara dengan cara yang paling mudah. Siswa merasa senang terhadap pelajaran bahasa Inggris karena diajarkan melalui strategi yang jauh lebih menyenangkan sehingga terdorong bagi siswa untuk belajar aktif dan kreatif. Apabila siswa sudah merasa senang, aktif dan kreatif terhadap mata pelajaran bahasa Inggris justru kemampuannya baik secara tertulis dan lisan akan meningkat. Dalam Ujian Nasional khususnya pelajaran bahasa Inggris tidak perlu dilakukan bantuan gratis (jawaban yang diberikan guru) melalui short messege system (SMS).

Tujuan Peningkatan Kemampuan Berbicara Bahasa Inggris Melalui Teknik Membaca Berita

1. Memberikan bermacam gambaran yang berkaitan dengan situasi siswa, proses pembelajaran, pengalaman belajar, pendidikan, sekolah, guru, kemajuan dan budaya, kelemahannya serta sikap siswa terhadap proses pembelajaran.

2. Menentukan informan yang tahu permasalahan dan berpengalaman dalam memberikan jawabanjawaban terutama yang menyangkut dengan keterampilan berbicara di dalam bahasa inggris

3. Mendorong setiap kelompok/individu dalam ruangan kelas untuk turut serta melakukan percakapan atau ikut memberikan tanggapan atas setiap pertanyaan yang muncul dari informan sehingga terkesan bahwa situasi ini benar-benar semua siswa tertarik untuk melakukan praktik keterampilan berbicara.

4. Menentukan topik pembicaran sesuai dengan materi pelajaran yang ada sehingga mampu dan mudah memecahkan pokok persoalan yang muncul. Selain topik yang ditentukan berhubungan dengan materi pelajaran, topik pembicaraan juga bisa ditampilkan atau disesuaikan dengan keadaan disekitar sekolah.

Ada tiga komponen yang harus menjadi sasaran utama pelatihan keterampilan berbicara bahasa inggris dalam membaca berita, yaitu siswa / pembelajaran, guru dan sekolah. Tiga komponen itulah yang akan menerima manfaat dari pelatihan ini. 


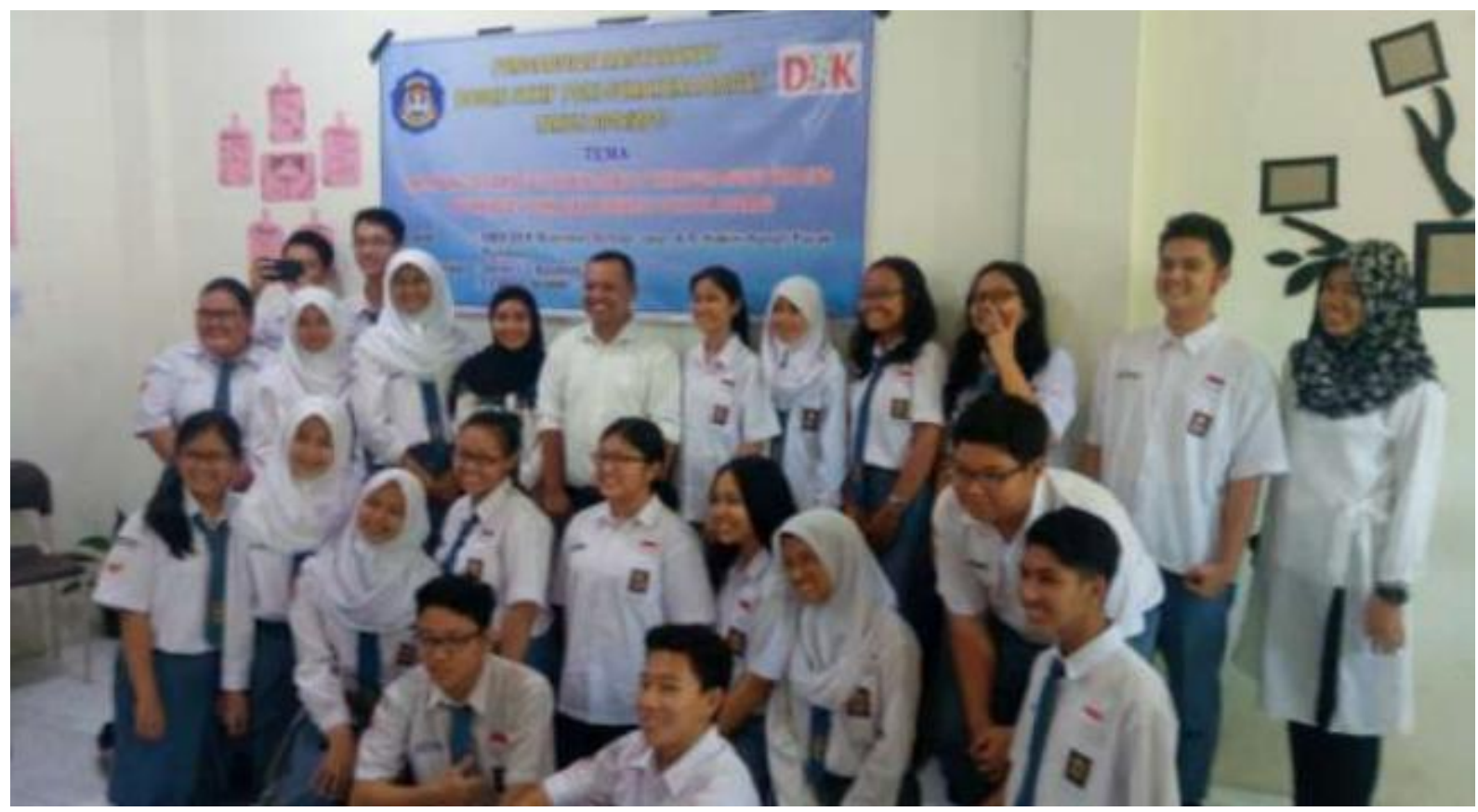

\section{SIMPULAN}

Mempelajari bahasa Inggris khususnya keterampilan berbicara membutuhkan bermacam strategi yang jitu. Tujuannya adalah mempermudah siswa mempelajari mata pelajaran bahasa Inggris, semakin banyak cara yang dilakukan untuk belajar maka semakin mudah menguasainya. Akan tetapi perlu diingat bahwa belajar bahasa Inggris bukan belajar pengetahuan yang memerlukan daya nalar yang tinggi, menghafal rumus-rumus, menguasai tenses, grammar, dan tata bahasa Inggris yang formal, dan lain-lain. Namun belajar bahasa Inggris tidak lebih dari keterampilan (skill) yang terus menerus dipraktikkan sampai terbiasa, bahasa apapun yang dipelajari membutuhkan praktik berbicara dengan bahasa yang dipelajari.

\section{DAFTAR PUSTAKA}

Guntur, Tarigan. 1986. Pengajaran kosakata. Bandung: Penerbit Angkasa.

Ibnu Hadjar. 1996. Dasar-Dasar Metodologi Penelitian Kuantitatif dalam Pendidikan. Jakarta: Raja Grafindo Persada.

Hall, S. 1997. Integrating pronunciation for fluency in presentation skills. ERIC Document, pp. 408-856.

Hamalik. 2003. PerananMotivasi terhadap Keberhasilan dalam Belajar. Bandung: Angkasa.

Sadli, Hassan. 1989. Kamus Inggris Indonesia-Indonesia Inggris. Jakarta

Hoskisson, K. \& Tompkins, G. E. 1987.Language arts: Content and teachingstrategies. Melbourne: Merill Publishing Company.

Hyland, K. 1991. Developing Oral Presentation Skills. Cambridge: Cambridge University Press. 